\title{
Consistency of Pacing and Metabolic Responses During 2000-m Rowing Ergometry
}

\author{
Thomas I. Gee, Duncan N. French, Karl C. Gibbon, and Kevin G. Thompson
}

\begin{abstract}
Purpose: This study investigated the pacing strategy adopted and the consistency of performance and related physiological parameters across three 2000-m rowing-ergometer tests. Methods: Fourteen male well-trained rowers took part in the study. Each participant performed three 2000-m rowing-ergometer tests interspersed by 3-7 d. Throughout the trials, respiratory exchange and heart rate were recorded and power output and stroke rate were analyzed over each $500 \mathrm{~m}$ of the test. At the completion of the trial, assessments of blood lactate and rating of perceived exertion were measured. Results: Ergometer performance was unchanged across the 3 trials; however, pacing strategy changed from trial 1, which featured a higher starting power output and more progressive decrease in power, to trials 2 and 3, which were characterized by a more conservative start and an end spurt with increased power output during the final $500 \mathrm{~m}$. Mean typical error (TE; \%) across the three $2000-\mathrm{m}$ trials was $2.4 \%$, and variability was low to moderate for all assessed physiological variables (TE range $=1.4-5.1 \%)$ with the exception of peak lactate $(\mathrm{TE}=11.5 \%)$. Conclusions: Performance and physiological responses during 2000-m rowing ergometry were found to be consistent over 3 trials. The variations observed in pacing strategy between trial 1 and trials 2 and 3 suggest that a habituation trial is required before an intervention study and that participants move from a positive to a reverse-J-shaped strategy, which may partly explain conflicting reports in the pacing strategy exhibited during 2000-m rowing-ergometer trials.
\end{abstract}

Keywords: rowers, reliability, pacing strategy, cardiorespiratory, time trial

Pacing strategy relates to the pattern by which energetic resources, mechanical power output, or speed is distributed during a bout of exercise. ${ }^{1} \mathrm{~A}$ growing body of evidence exists with regard to the pacing strategy used by trained rowers performing a 2000-m rowing-ergometer test or on-water race. ${ }^{2-5}$ Traditionally, a reverse-J-shaped pacing strategy has been observed for $2000-\mathrm{m}$ rowing. ${ }^{2-4}$ This strategy is characterized by a high power output during the initial phase, followed by a decrease in power output in the middle of the event, followed by an end spurt in the final stages, which is completed with a higher power output than the middle phase but lower than the initial phase. ${ }^{6}$ The powerful start, as featured in this strategy, is tactically and psychologically advantageous in rowing, as gaining placement at the front of the race will allow rowers, who look backward down the course, to be able to monitor the position of other boats and react to any sudden advances from other competitors and also avoid the wake of other boats. ${ }^{3}$ The reverse-J-shaped strategy is firmly established for on-water rowing races ${ }^{2,3}$; however, there is conflicting evidence regarding the pacing strat-

Gee is with the School of Sport and Exercise Science, University of Lincoln, Lincoln, UK. French, and Gibbon are with the School of Life Sciences, Northumbria University, Newcastle, UK. Thompson is with the Faculty of Health, University of Canberra, ACT, Australia. egy during 2000-m ergometer rowing. Researchers have reported a positive pacing strategy, characterized by a fast start and gradual decline in speed throughout the event, ${ }^{6}$ in national-level rowers and high school rowers ${ }^{2,4}$ and a reverse-J-shaped strategy in both elite and well-trained rowers and physically active participants (nonrowers). $2,5,7$

Although there is conflicting evidence regarding pacing during 2000-m rowing ergometry, the test itself has proved to have good reproducibility across repeated trials (typical error $[\%]=1.8-2.0 \%){ }^{4,5}$ However, participants in these studies had considerably slower $2000-\mathrm{m}$ performance times (6:51-6:56 and 6:58 min:s) than reported from club-standard rowers of a similar body mass taking part in research studies (6:33.7-6:38.6 min:s).$^{8-10}$ The rowing experience and performance level of the rowers used in the studies by Schabort et $\mathrm{al}^{4}$ and Soper and Hume $\mathrm{H}^{5}$ might not be representative of well-trained senior club rowers. Therefore, the reproducibility of 2000-m ergometer performance in rowers of a higher standard is not yet known. In addition, the smallest practical effect, which allows for quantification of the probability of a practical change in performance occurring, ${ }^{11}$ has not been reported for 2000-m rowingergometer performance. Calculating the smallest practical effect is necessary to distinguish whether real changes have occurred over time for subsequent testing periods. ${ }^{12}$

Recently several authors have investigated the reproducibility of power and metabolic responses 
during cycling time trials. ${ }^{1,13,14}$ Those authors analyzed performance and physiological variables per phase of the event, which allows for intricate analysis of varying trends in pacing and their causality from the analysis of metabolic responses. Corbett et $\mathrm{al}^{13}$ and Thomas et $\mathrm{al}^{14}$ have shown that pacing strategy is modified from trial 1 to trials 2 and 3, with accompanying changes in energy liberation characteristics in the study by Corbett et al. ${ }^{13}$ The authors theorized that the changes in pacing after trial 1 were consistent with the concept of an intelligent, complex regulatory system described by the central governor model, where information gained from the first trial is used to change the exercise template, either consciously or subconsciously, on subsequent bouts. ${ }^{15,16}$ In relation to rowing, Schabort et $\mathrm{al}^{4}$ and Foster et $\mathrm{al}^{7}$ also reported changes in pacing strategy from trial 1 to trials 2 and 3; however, the authors did not carry out any cardiorespiratory analysis during the trials, so physiological interpretation of the observed findings was restricted.

This is the first study to investigate intricate metabolic responses while assessing the reproducibility of 2000-m ergometer performance, therefore enabling greater understanding of the mechanisms underlying pacing strategy during rowing. The principal aims were to investigate the pacing strategy adopted and distribution of energetic resources across three 2000-m tests and to investigate the consistency of performance and related physiological parameters across three 2000-m ergometer tests in trained club rowers. We hypothesized that $2000-\mathrm{m}$ ergometer performance would be consistent across repeated trials, anticipating that a reverse-J-shaped pacing strategy would be demonstrated during the three 2000-m trials.

\section{Methods}

\section{Participants}

Fourteen male well-trained competitive club rowers volunteered to take part in the study. Mean age $( \pm$ SD) of the participants was $22.8(5.1)$ years, height $1.86(0.05) \mathrm{m}$, mass $85.6(8.3) \mathrm{kg}, 2000-\mathrm{m}$ rowing-ergometer time 6:33.9 (0:09.5) min:s, rowing experience 7.1 (5.1) years. All participants had extensive prior experience at performing 2000-m ergometer tests before their involvement in the study. Participants provided written informed consent to participate in the study, which was approved by the local ethics committee.

\section{0-m Rowing-Ergometer Test}

The study followed a repeated-measures design to determine the consistency of 2000-m rowing-ergometer performance, pacing, and metabolic responses. Each participant performed three 2000-m rowing-ergometer tests with 3 to 7 days between testing sessions. For each trial, participants were asked to arrive at the laboratory in a hydrated state having abstained from exercise on the day of testing. The test was performed on an air-braked rowing ergometer (Concept 2 Model C, Concept 2 Ltd,
Wilford, Notts, UK) with a drag factor of 140 (in accordance with the British International Rowing guidelines for ergometer testing). ${ }^{9}$ Before the initiation of each trial, participants were allocated a 5-minte warm-up on the rowing ergometer. During each trial, the only feedback given to participants was the stroke rate and distance remaining. ${ }^{4}$ Expired breath-by-breath respiratory-gas-exchange parameters $\left(\mathrm{VO}_{2}\right.$ and $\left.\mathrm{VCO}_{2}\right)$ were measured continuously using an automated online metabolic cart (Cortex, Metalyzer, Leipzig, Germany), which has previously been demonstrated to be a valid and reliable instrument for measuring such parameters during exercise. ${ }^{17}$ Contributions of aerobic $\left(P_{\text {aer }}\right)$ and anaerobic metabolism $\left(P_{\text {anaer }}\right)$ to mean total power $\left(P_{\text {tot }}\right)$ during each $500-\mathrm{m}$ stage were calculated according to methods previously described ${ }^{18}$ using an established exercise efficiency for trained rowers performing 2000-m ergometer testing. ${ }^{19}$ Heart rate (HR) was recorded every 10 seconds during the test using the Polar monitoring system (Polar Accurex Plus, Polar Electro, Kempele, Finland). Participants reported their rating of perceived exertion (RPE; 6-20 scale) ${ }^{20}$ immediately after the test was completed. Duplicate fingertip capillary blood samples of $20 \mu \mathrm{L}$ were drawn for the assessment of blood lactate $\left[\mathrm{La}^{-}\right]$at the completion of the test and at 1 , 3,5 , and 7 minutes of recovery. The Biosen C_Line Sport ( 2 channel) $\left[\mathrm{La}^{-}\right]$and glucose analyzer (EKF Diagnostic, Barleben, Germany), which has detection limits of 0.5 to $40.0 \mathrm{mmol} / \mathrm{L}$, was used for analysis.

\section{Statistical Analysis}

Data from the metabolic cart $\left(\mathrm{VO}_{2}\right.$, respiratory-exchange ratio) were interpolated and averaged over 1 -second intervals. Measures of time, power, and stroke rate were obtained for whole-trial performance and per $500 \mathrm{~m}$ of the trial duration from the rowing ergometer's digital monitor. Descriptive statistics are presented as mean $( \pm$ SD) unless otherwise stated. Statistical analyses were conducted using SPSS 16.0 (Chicago, IL) with the alpha level for significance set at $P<.05$. A 1 -way ANOVA was used to investigate between-trials differences in whole-trial performance and assessed physiological measures $\left(\mathrm{VO}_{2}\right.$, $\mathrm{VCO}_{2}$, respiratory-exchange ratio, $\mathrm{HR},\left[\mathrm{La}^{-}\right]$, and RPE). Typical error as a percentage (TE \%; $90 \%$ confidence intervals) for whole-trial performance and physiological measures was derived from log-transformed data and established using a spreadsheet produced by Hopkins. ${ }^{21}$ In assessing the variability of performance and physiological measures during endurance time trials, low and moderate TEs have been defined as under $2 \%^{1,22}$ and $3 \%$ to $10 \%,{ }^{1}$ respectively. Smallest practical effect was calculated for 2000-m performance from the product of 0.3 (which represents the smallest standardized change in mean for a group of trained participants $)^{11}$ multiplied by the between-participants SD across the 3 trials.

To describe any differences in the pacing strategy, the test data were divided into $4 \times 500$-m stages. A $3 \times$ 4 (trial $\times$ stage) repeated-measures ANOVA was used to investigate differences in pacing strategy, which featured 
assessment of $P_{\text {tot }}, P_{\text {aer }}, P_{\text {anaer }}, \mathrm{VO}_{2}(\mathrm{~L} / \mathrm{min})$, and stroke rate. Assumptions of sphericity were assessed using the Mauchly test of sphericity, with any violations adjusted by use of the Greenhouse-Geisser (GG) correction. If a significant main effect across time was shown, post hoc differences across trials were analyzed with use of the least-significant-difference correction. Effect size (ES) was calculated for any nonstatistically significant result trends $(P=.051-.10)$ in accordance with procedures suggested by Hopkins. ${ }^{23}$

\section{Results}

There were no differences in performance time across the three 2000-m trials; furthermore, there were no changes in any of the assessed physiological measures (Table 1). In addition, the mean typical error across trials 1 to 3 for all assessed variables was low to moderate (range 1.4-5.1\%) with the exception of [ $\left.\mathrm{La}^{-}\right]$(Table 1). In relation to the stages of the 2000-m test, typical error was greatest during the initial 500-m stage of the test (Table 2 ) and higher in the second stage than in stages 3 and 4.

There were significant within-trial differences for $P_{\text {tot }}$ $\left(F_{\mathrm{GG}}=57.63, P=.000\right), P_{\mathrm{aer}}\left(F_{\mathrm{GG}}=156.57, P=.000\right)$, and $P_{\text {anaer }}\left(F_{\mathrm{GG}}=166.81, P=.000 ;\right.$ Figure 1$)$. In relation to pacing strategy, pairwise comparisons revealed that a fast start was adopted by participants during the first 500-m stage, with power output (391 [27] W) being significantly greater than in the 3 latter 500-m stages (stage 2, 336 [24] W; stage 3, 320 [24] W; stage 4, 336 [34] $\mathrm{W})$. The mean power during the third 500-m stage was found to be significantly lower than in stages 2 and 4 . In relation to $P_{\text {aer }}$, stage 1 included the lowest power (207 [17]), with no differences between the following 3 stages (258-261 [21-23] W). For $P_{\text {anaer }}$, stage 1 had the highest power (184 [25] W), while stage 3 featured the lowest power output (60 [21] W), with no differences in power between stages 2 (78 [20] W) and 4 (74 [29] W). There were within-trial differences for $\mathrm{VO}_{2}\left(F_{\mathrm{GG}}=178.18, P=\right.$ $.000)$. $\mathrm{VO}_{2}$ was lower during the initial $500 \mathrm{~m}$ of the test $(4.26[0.37] \mathrm{L} / \mathrm{min})$ than during the remaining $1500 \mathrm{~m}$ (5.27-5.34 [0.44-0.48] L/min). There were differences in stroke rate between 500 -m stages during the 2000 -m test ( $F=40.18, P=.000)$, with the rate being highest during the first stage (32 [1] strokes/min), before significantly decreasing to 29 (1) strokes/min during phases 2 and 3 and then significantly increasing to 30 (1) strokes/min during the final stage.

There were significant trial $\times$ stage effects for $P_{\text {tot }}$ $\left(F_{\mathrm{GG}}=5.83, P=.006\right)$ and $P_{\text {anaer }}\left(F_{\mathrm{GG}}=3.36, P=.032\right.$; Figure 1). Mean power for the initial 500-m stage in trial

Table 1 Whole-Trial Performance and Physiological Measures During Each Trial as Mean (SD) and Associated Typical Error (TE) as \% (90\% Confidence Interval) for Trials 1-2, 2-3, and as a Mean Across All Trials

\begin{tabular}{lcccccc}
\hline & Trial 1 & Trial 2 & Trial 3 & TE T1-T2 (\%) & TE T2-T3 (\%) & Mean TE (\%) \\
\hline Time, s & $402.5(9.6)$ & $403.9(9.4)$ & $401.7(10.0)$ & $0.6(0.5-0.9)$ & $0.9(0.7-1.4)$ & $0.8(0.7-1.1)$ \\
Mean power, W & $347(24)$ & $343(24)$ & $348(26)$ & $1.8(1.4-2.7)$ & $2.9(2.2-4.4)$ & $2.4(2.0-3.4)$ \\
Mean stroke rate, strokes/min & $30(1)$ & $30(1)$ & $30(2)$ & $2.8(2.1-4.1)$ & $3.1(2.3-4.6)$ & $2.9(2.4 .4 .0)$ \\
Peak $\mathrm{VO}_{2}$ L/min & $6.03(0.62)$ & $5.96(0.62)$ & $6.04(0.62)$ & $4.1(3.1-6.2)$ & $4.5(3.4-6.7)$ & $4.3(3.5-6.0)$ \\
${\text { Mean } \mathrm{VO}_{2}, \mathrm{~L} / \mathrm{min}}^{5.09(0.50)}$ & $5.01(0.41)$ & $5.03(0.51)$ & $4.2(3.2-6.3)$ & $5.8(4.4-8.7)$ & $5.1(3.9-7.7)$ \\
${\text { Mean } \mathrm{VCO}_{2}, \mathrm{~L} / \mathrm{min}}_{\text {Mean respiratory-exchange ratio }}$ & $1.13(0.04)$ & $1.12(0.05)$ & $1.12(0.08)$ & $2.3(1.7-3.4)$ & $2.4(1.8-3.6)$ & $2.3(1.9-3.2)$ \\
Peak heart rate, beats/min & $192(6)$ & $190(6)$ & $191(6)$ & $1.5(1.1-2.3)$ & $1.2(0.9-1.8)$ & $1.4(1.1-1.9)$ \\
Mean heart rate, beats/min & $182(6)$ & $179(6)$ & $180(6)$ & $1.7(1.3-2.5)$ & $1.7(1.3-2.5)$ & $1.7(1.4-2.3)$ \\
Peak lactate, mmol/L & $18.6(3.8)$ & $16.3(3.5)$ & $17.2(3.1)$ & $7.5(5.7-11.4)$ & $14.5(10.9-22.3)$ & $11.5(9.3-16.2)$ \\
Rating of perceived exertion & $17(1)$ & $17(1)$ & $17(1)$ & $4.1(3.1-6.1)$ & $5.0(3.8-7.5)$ & $4.5(3.7-6.3)$ \\
\hline
\end{tabular}

Table 2 Typical Error for Trials 1-2, 2-3, and Mean Across All Trials for Power Output During Successive 500-m Stages During the 2000-m Ergometer test, \% (90\% Confidence Interval)

\begin{tabular}{lccc}
\hline Stage & Trial 1-2 & Trial 2-3 & Mean TE \\
\hline $0-500 \mathrm{~m}$ & $4.3(3.2-6.4)$ & $7.6(5.8-11.5)$ & $6.2(5.0-8.6)$ \\
$500-1000 \mathrm{~m}$ & $4.1(3.1-6.1)$ & $4.1(3.1-6.2)$ & $4.1(3.4-5.7)$ \\
$1000-1500 \mathrm{~m}$ & $3.1(2.4-4.7)$ & $2.6(2.0-3.9)$ & $2.9(2.4-4.0)$ \\
$1500-2000 \mathrm{~m}$ & $2.9(2.2-4.3)$ & $3.1(2.4-4.7)$ & $3.0(2.5-4.2)$ \\
\hline
\end{tabular}




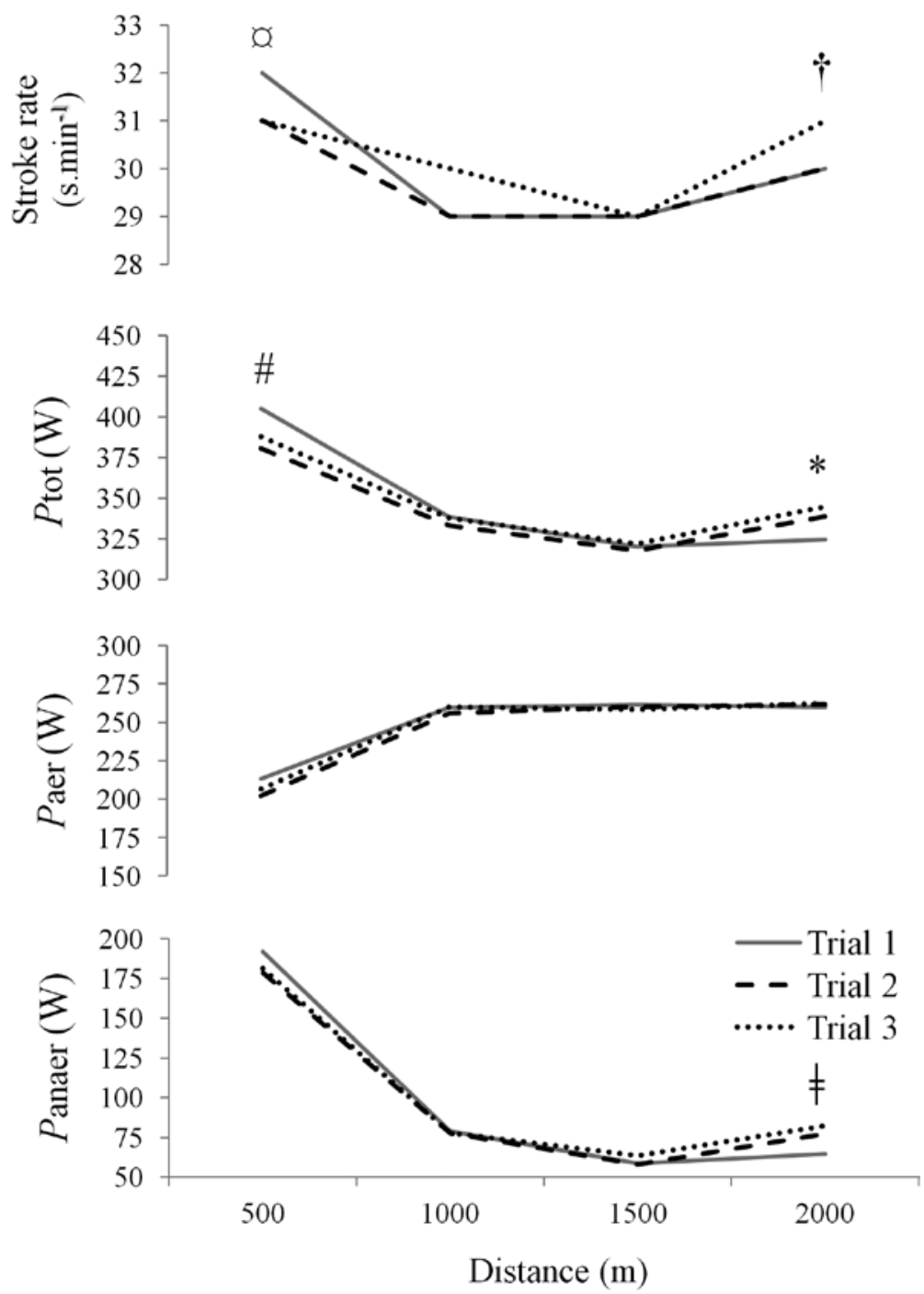

Figure 1 - Serial pattern of stroke rate (strokes/min) and anaerobic (Panaer) and aerobic $(P$ aer $)$ contributions to total power $(P$ tot $)$ during repeat $2000-\mathrm{m}$ trials. *Trial 1 significantly different $(P<.05)$ than trials 2 and 3 . \#Significant difference $(P<.05)$ between trials 1 and 2 and trend for difference $(P<.10)$ between trials 1 and $3 . \neq$ Significant difference $(P<.05)$ between trials 1 and 3 and trend for difference $(P<.10)$ between trials 1 and 2 . QTrial 1 significantly different $(P<.05)$ than trial 2 . † Significant difference $(P<.05)$ between trials 1 and 3 and trend for difference $(P<.10)$ between trials 2 and 3 .

$1(405[35] \mathrm{W})$ was higher than in trial $2(381[32] \mathrm{W}, P$ $=.002)$ and demonstrated a trend toward a higher value than trial $3(388[32] \mathrm{W}, P=.078, E S=0.50)$. There was a concomitant increase in power during the final $500 \mathrm{~m}$ for trials $2(339[35] \mathrm{W})$ and $3(345$ [36] W) relative to trial $1(325[32] \mathrm{W}, P<.01)$, indicating the presence of an end spurt in trials 2 and 3 . The changes between trials for $P_{\text {anaer }}$ somewhat mirrored those of $P_{\text {tot }}$; there was a trend for $P_{\text {anaer }}$ to be higher during stage 1 for trial 1 than for trial 2 (192 [35] W vs 178 [23] W, $P=.091, E S=0.47)$. However, during stage $4 P_{\text {anaer }}$ was lower for trial 1 (65 [28] W) than trials $2(77[31] \mathrm{W}, P=.063, E S=0.41)$ and $3(82$ [38] W, $P=.012)$. A significant trial $\times$ stage effect was present for stroke rate $(F=3.04, P=.010)$. For stage 1 , stroke rate was significantly higher during trial 1 than during trial 2 (32 [1] W vs 31 [1] W, $P=.007)$, whereas for stage 4 stroke rate was higher for trial 3 (31 [1] W) than either trial $1(30[1] \mathrm{W}, P=.015)$ or trial 2 (30 [2] $\mathrm{W}, P=.065, E S=0.59$ ).

\section{Discussion}

The principal aims of this study were to investigate the pacing strategy and distribution of energetic resources across three 2000-m ergometer tests and to investigate the consistency of performance and related physiological parameters. For the first trial, participants followed a positive pacing strategy where power output was highest during stage 1 , then declined on average by $66 \mathrm{~W}$ during 
stage 2 , and then by a further $\sim 20 \mathrm{~W}$ for stages 3 and 4 . Our results indicate that an adjustment in pacing strategy was made after this first trial. This was characterized by a reduction in power output during the initial $500 \mathrm{~m}$ for trials 2 and 3, which conserved anaerobic energy that was subsequently expended during the final $500 \mathrm{~m}$ and afforded a higher power output, which led to an end spurt during trials 2 and 3 . This strategy is characterized as a reverse-J-shaped model of pacing, and its use is established in on-water rowing races. ${ }^{2,3}$ It has been proposed that athletes with greater familiarity with an exercise task will display an end spurt of decreased amplitude, which indicates an increased efficiency in the use of energetic resources. ${ }^{14}$ Accordingly, the observed end spurt during 2000-m rowing displayed by trained rowers in the current study and in studies by Brown et $\mathrm{al}^{2}$ and Schabort et $\mathrm{al}^{4}$ was much less pronounced than in relation to inexperienced rowers as featured by Foster et al. ${ }^{7}$

The rowers in the current study had extensive experience at performing 2000-m tests in training; therefore, it was assumed that they would have an established model of pacing for this test. However, the participating rowers did not have prior experience of performing physiological research, so this presented an unfamiliar environment for the performance of the 2000-m tests. Schabort et $\mathrm{al}^{4}$ have previously attributed familiarization with the laboratory testing environment to an enhanced and more consistent 2000-m rowing performance. It is likely that the unfamiliar respiratory apparatus and other factors (time in training cycle) affected the $2000-\mathrm{m}$ performance of participants, with mean performance time increased by $\sim 9$ seconds across the 3 trials compared with reported personal-best times for the 2000-m test. The rowers reported near-maximal efforts (RPE 17 [1]), and the measured physiological responses would suggest they provided near-maximal or maximal efforts in the experimental trials. Given that subjects may not produce maximal efforts under laboratory conditions ${ }^{24}$ and as they were not tapering for competition at the time of the study, we believe this variation to be acceptable. The data show that in relation to planning rowing-based physiological intervention studies, it is important for researchers to consider the changes in pacing strategy that can occur across repeated 2000-m ergometer trials independent of any intervention. When considering the results from the current study it is imperative that one familiarization trial be undertaken when carrying out intervention studies featuring a 2000-m ergometer test in trained rowers, as has recently been suggested for cycling time trials. ${ }^{14}$

There was no adjustment in pacing profile from trials 2 and 3 , indicating that sufficient prior experience was gained in the first trial to allow the participants to adopt an assumed optimal strategy for the subsequent trials. However, despite these shifts in pacing strategy from trial 1, there was no difference in performance time across the 3 trials. This is in contrast to findings by Schabort et al, ${ }^{4}$ who showed that changes in pacing strategy for a 2000-m row after trial 1 were matched with performance improvements in trials 2 and 3. However, the findings are in agreement with those of Corbett et al, ${ }^{13}$ who found no performance improvements in 2000-m cycling performance despite participants' changing from a positive pacing strategy in trial 1 to a reverse-J-shaped strategy in trials 2 and 3 . The current findings are in accordance with the concept of an intelligent regulatory pacing mechanism as described as the central governor model, ${ }^{15,16}$ as data suggest that feedback gained from the first trial were used to modify the exercise template, either consciously or subconsciously, to decrease the power produced during stage 1 on trials 2 and 3 . The higher power produced during stage 1 for trial 1 likely caused levels of discomfort due to metabolite accumulation, heightening afferent feedback and informing the pacing algorithm for subsequent trials. ${ }^{25}$ This adjustment in pacing led to a decrease in stage 1 power for trials 2 and 3. This interpretation remains speculative, although the increase in anaerobic-energy contribution observed in trials 2 and 3 relative to trial 1 toward the end of the trial would indicate a reduction in the use of the finite $\mathrm{W}$ (work performed at an intensity above the maximal lactate steady state) earlier in the trial. ${ }^{26}$

The TE for mean power recorded from trials 1 to 2 (1.8\%), 2 to $3(2.9 \%)$, and overall (2.4\%) indicates good reproducibility across repeated trials, which concurs with our experimental hypothesis. TE was similar to that reported by Schabort et $\mathrm{al}^{4}$ and Soper and Hume 5 (1.8-2.0\%). The assessed physiological measures in the current study demonstrated good to moderate reproducibility (mean TE $=1.4-5.1 \%$ ) with the exception of $\left[\mathrm{La}^{-}\right]$ $(11.5 \%)$. These findings are similar to those reported by Stone et $\mathrm{al}^{1}$ and Thomas et al, ${ }^{14}$ who had trained cyclists perform repeated time trials and found low to moderate variability in physiological measures (1.2-8.0\%) but greater variability in $\left[\mathrm{La}^{-}\right](9.6-17.7 \%)$. Swart and Jennings ${ }^{27}$ concluded that changes in $\left[\mathrm{La}^{-}\right]$should be interpreted with caution, as the changes do not track training status or exercise intensity with sufficient precision to have a practical application. Across the 3 trials, mean recorded $\mathrm{VO}_{2}$ values were higher $(\sim 5.0 \mathrm{~L} / \mathrm{min})$ than previously reported in rowers of a similar standard ( 4.5-4.6 L/min $)^{28,29}$; however, the participants in the current study had a higher body mass, so larger absolute $\mathrm{VO}_{2}$ values would be expected.

To our knowledge, this is the first study to report contributions of aerobic and anaerobic metabolism to total power per segment of a 2000-m rowing trial. The within-trial serial changes of $P_{\text {aer }}$ and $P_{\text {anaer }}$ followed a pattern that would be expected given the pacing characteristics of the $2000-\mathrm{m}$ test. The initial $500 \mathrm{~m}$ of $2000-\mathrm{m}$ rowing trials has consistently been found to be the most powerful phase $\mathrm{e}^{2-5}$ and unsurprisingly featured the greatest anaerobic-energy liberation. In accordance with the reverse-J-shaped pacing model, $P_{\text {anaer }}$ decreased during stage 3 , allowing a reserve of anaerobic energy to be used in stage $4 .^{6}$ The concomitant maintenance of $P_{\text {aer }}$ and hence $\mathrm{VO}_{2}$ within a narrow range during stages 2,3 , and 4 indicates that the peak for oxidative energy liberation was achieved in the second stage. These findings concur with 
those of Corbett et al, ${ }^{13}$ who found that variations in power output during a 2000-m cycling time trial were caused by altering the pattern of anaerobic-energy distribution.

In relation to power output, the smallest practical effect was $8 \mathrm{~W}$, equivalent to $2.3 \%$, which was slightly lower than the mean TE across the 3 trials of $2.4 \%$. Therefore, an improvement in 2000-m performance of $2.5 \%$, or $9 \mathrm{~W}$, would be regarded as a meaningful change in performance, as this is greater than both the TE and the smallest practical effect. This meaningful-change value expressed in relation to $2000-\mathrm{m}$ completion time is equivalent to 3.3 seconds. With use of methods described by Hopkins ${ }^{12}$ the sample-size requirements for a study using a particular protocol can be estimated from knowledge of the TE and smallest practical effect. Using the equation proposed by Hopkins, ${ }^{12}$ the data presented in the current study indicate a minimum sample size of 10 participants to detect $80 \%$ power in a crossover or simple test-retest design. If a control group is used, the minimum requirement is 38 participants.

\section{Practical Applications}

Performance and assessment of relevant physiological measures were consistent across repeated 2000-m rowing-ergometer trials, so the test can be confidently used in the physiological monitoring of well-trained rowers. However, caution should be taken when carrying out physiological intervention studies involving this test with participants who are unaccustomed to such environments, since changes in pacing strategy were shown from trial 1 to trials 2 and 3 . Therefore, a habituation trial is recommended, as a single trial appears to provide sufficient prior experience for a reproducible pacing strategy thereafter. Our results indicate that an improvement in mean power during 2000-m ergometer performance of $2.5 \%$, or $9 \mathrm{~W}$, signifies a real and practical change in performance. This threshold value should be considered by rowing coaches and physiologists when interpreting rowers' performance during 2000-m ergometer testing.

\section{Conclusions}

In summary, performance and physiological responses during 2000-m rowing ergometry in well-trained rowers were found to be consistent over 3 trials. The participants in this study were unaccustomed to the research-driven testing environment, which may have caused the observed changes in pacing strategy from trial 1 to trials 2 and 3 . These subtle changes in pacing strategy might be related to changes in anaerobic-energy metabolism.

\section{Acknowledgments}

Funding for this research was provided by the Research and Development Fund, Northumbria University. The authors would like to thank the rowers who volunteered to participate in the research.

\section{References}

1. Stone MR, Thomas K, Wilkinson M, St Clair Gibson A, Thompson KG. Consistency of perceptual and metabolic responses to a laboratory-based simulated 4,000-m cycling time trial. Eur J Appl Physiol. 2011;111:1807-1813. PubMed doi:10.1007/s00421-010-1818-7

2. Brown MR, Delau S, Desgorces FD. Effort regulation in rowing races depends on performance level and exercise mode. J Sci Med Sport. 2010;13:613-617. PubMed doi:10.1016/j.jsams.2010.01.002

3. Garland SW. An analysis of the pacing strategy adopted by elite competitors in $2000 \mathrm{~m}$ rowing. Br J Sports Med. 2005;39:39-42. PubMed doi:10.1136/bjsm.2003.010801

4. Schabort EJ, Hawley JA, Hopkins WG, Blum H. High reliability of performance of well-trained rowers on a rowing ergometer. J Sports Sci. 1999; 17:627-632. PubMed doi:10.1080/026404199365650

5. Soper C, Hume PA. Reliability of power output during rowing changes with ergometer type and race distance. Sports Biomech. 2004;3:237-248. PubMed doi:10.1080/14763140408522843

6. Abbiss CR, Laursen PB. Describing and understanding pacing strategies during athletic competition. Sports Med. 2008;38:239-252. PubMed doi:10.2165/00007256200838030-00004

7. Foster C, Hendrickson KJ, Peyer K, et al. Pattern of developing the performance template. Br J Sports Med. 2009;43:765-769. PubMed doi:10.1136/bjsm.2008.054841

8. Gee TI, French DN, Howatson G, Payton SJ, Berger NJ, Thompson KG. Does a bout of strength training affect 2,000 $\mathrm{m}$ rowing ergometer performance and rowingspecific maximal power 24 h later? Eur J Appl Physiol. 2011;111:2653-2662. PubMed doi:10.1007/s00421-0111878-3

9. Ingham SA, Carter H, Whyte GP, Doust JH. Comparison of the oxygen uptake kinetics of club and Olympic champion rowers. Med Sci Sports Exerc. 2007;39:865-871. PubMed doi:10.1249/mss.0b013e31803350c7

10. Ingham SA, Carter H, Whyte GP, Doust JH. Physiological and performance effects of low- versus mixed-intensity rowing training. Med Sci Sports Exerc. 2008;40:579-584. PubMed doi:10.1249/MSS.0b013e31815ecc6a

11. Hopkins WG, Marshall SW, Batterham AM, Hanin J. Progressive statistics for studies in sports medicine and exercise science. Med Sci Sports Exerc. 2009;41:3-13. PubMed

12. Hopkins WG. Measures of reliability in sports medicine and science. Sports Med. 2000;30:1-15. PubMed doi:10.2165/00007256-200030010-00001

13. Corbett J, Barwood MJ, Parkhouse K. Effect of task familiarisation on distribution of energy during a 2000 m cycling time trial. Br J Sports Med. 2009;43:770-774. PubMed doi:10.1136/bjsm.2008.056416

14. Thomas K, Stone MR, Thompson KG, St Clair Gibson A, Ansley L. Reproducibility of pacing strategy during simulated 20-km cycling time trials in well-trained cyclists. Eur J Appl Physiol. 2012;112:223-229. PubMed doi:10.1007/ s00421-011-1974-4 
15. Noakes TD, St Clair Gibson A, Lambert EV. From catastrophe to complexity: a novel model of integrative central neural regulation of effort and fatigue during exercise in humans. Br J Sports Med. 2004;38:511-514. PubMed doi:10.1136/bjsm.2003.009860

16. St Clair Gibson A, Lambert EV, Rauch LH, et al. The role of information processing between the brain and peripheral physiological systems in pacing and perception of effort. Sports Med. 2006;36:705-722. PubMed doi:10.2165/00007256-200636080-00006

17. Meyer T, Davison RC, Kindermann W. Ambulatory gas exchange measurements - current status and future options. Int J Sports Med. 2005;26(Suppl 1):S19-S27. PubMed doi:10.1055/s-2004-830507

18. de Koning JJ, Bobbert MF, Foster C. Determination of optimal pacing strategy in track cycling with an energy flow model. J Sci Med Sport. 1999;2:266-277. PubMed doi:10.1016/S1440-2440(99)80178-9

19. Hagerman FC, Connors MC, Gault JA, Hagerman GR, Polinski WJ. Energy expenditure during simulated rowing. J Appl Physiol. 1978;45:87-93. PubMed

20. Borg G. Perceived exertion as an indicator of somatic stress. Scand J Rehabil Med. 1970;2:92-98. PubMed

21. Hopkins WG. Analysis of reliability with a spreadsheet: a new view of statistics. 2007. http://sportsci.org/resource/ stats/xrely.xls.

22. Hopkins WG, Schabort EJ, Hawley JA. Reliability of power in physical performance tests. Sports Med. 2001;31:211234. PubMed doi:10.2165/00007256-200131030-00005
23. Hopkins WG. A spreadsheet for analysis of straightforward controlled trials. Sportscience. 2003;7. http://www. sportsci.org/jour/03/wghtrials.htm.

24. Hopkins WG, Hawley JA, Burke LM. Design and analysis of research on sport performance enhancement. Med Sci Sports Exerc. 1999;31:472-485. PubMed doi:10.1097/00005768-199903000-00018

25. Baden DA, McLean TL, Tucker R, Noakes TD, St Clair Gibson A. Effect of anticipation during unknown or unexpected exercise duration on rating of perceived exertion, affect, and physiological function. Br J Sports Med. 2005;39:742-746, discussion 742-746. PubMed doi:10.1136/bjsm.2004.016980

26. Burnley M, Jones AM. Oxygen uptake kinetics as a determinant of sports performance. Eur J Sport Sci. 2007;7:63-79. doi:10.1080/17461390701456148

27. Swart J, Jennings CL. Use of blood lactate concentration as a marker of training status: review article. S Afr J Sports Med. 2004;16:1-5.

28. Russell AP, Le Rossignol PF, Sparrow WA. Prediction of elite schoolboy $2000 \mathrm{~m}$ rowing ergometer performance from metabolic, anthropometric and strength variables. J Sports Sci. 1998;16:749-754. PubMed doi:10.1080/026404198366380

29. de Campos Mello F, de Moraes Bertuzzi R, Grangeiro P, Franchini E. Energy systems contributions in 2,000 $\mathrm{m}$ race simulation: a comparison among rowing ergometers and water. Eur J Appl Physiol. 2009;107:615-619. PubMed doi:10.1007/s00421-009-1172-9 